\title{
Mutational analysis of human elF4AIII identifies regions necessary for exon junction complex formation and nonsense-mediated mRNA decay
}

\author{
TOSHIHARU SHIBUYA, THOMAS Ø. TANGE, M. ELIZABETH STROUPE, and MELISSA J. MOORE \\ Howard Hughes Medical Institute, Department of Biochemistry, Brandeis University, Waltham, Massachusetts 02454, USA
}

\begin{abstract}
The exon junction complex (EJC) is deposited on mRNAs by the process of pre-mRNA splicing and is a key effecter of downstream mRNA metabolism. We previously demonstrated that human elF4AIII, which is essential for nonsense-mediated mRNA decay (NMD), constitutes at least part of the RNA-binding platform anchoring other EJC components to the spliced mRNA. To determine the regions of eIF4AIII that are functionally important for EJC formation, for binding to other EJC components, and for NMD, we now report results of an extensive mutational analysis of human eIF4AIII. Using GFP-, GSTor Flag-fusions of eIF4AIII versions containing site-specific mutations or truncations, we analyzed subcellular localizations, protein-protein interactions, and EJC formation in vivo and in vitro. We also tested whether mutant proteins could rescue NMD inhibition resulting from RNAi depletion of endogenous elF4AIII. Motifs la and VI, which are conserved among the elF4A family of RNA helicases (DEAD-box proteins), are crucial for EJC formation and NMD, as is one elF4AIII-specific region. An additional eIF4AIII-specific motif forms part of the binding site for MLN51, another EJC core component. Mutations in the canonical Walker A and B motifs that eliminate RNA-dependent ATP hydrolysis by elF4AIII in vitro are of no detectable consequence for EJC formation and NMD activation. Implications of these findings are discussed in the context of other recent results and a new structural model for human eIF4AIII based on the known crystal structure of Saccharomyces cerevisiae eIF4AI.
\end{abstract}

Keywords: EJC; pre-mRNA splicing; NMD; eIF4AIII; MLN51; Magoh; Y14

\section{INTRODUCTION}

Most metazoan genes are interrupted by at least one intervening sequence or intron, with human genes containing on average 10 such sequences (Lander et al. 2001; Venter et al. 2001). Upon transcription, these introns must be precisely excised from nascent pre-mRNAs to generate functional mRNAs. It is now clear that the nuclear process of premRNA splicing can profoundly influence numerous downstream events in the cytoplasm, including mRNA localization, translational yield, and decay (Dreyfuss et al. 2002; Le Hir et al. 2003; Tange et al. 2004). The species responsible for these downstream effects is the exon junction complex (EJC), a set of proteins deposited 20-24 nucleotides (nt) upstream of exon-exon junctions as a consequence of pre-mRNA splicing (Le Hir et al. 2000). Splicing-dependent effects spe-

Reprint requests to: Melissa J. Moore, Howard Hughes Medical Institute, Department of Biochemistry, MS009, Brandeis University, 415 South Street, Waltham, MA 02454, USA; e-mail: mmoore@brandeis.edu; fax: (781) 736-2337.

Article and publication are at http://www.rnajournal.org/cgi/doi/ 10.1261/rna.2190706. cifically attributed to the EJC, or one or more of its components, include enhanced nuclear export of spliced RNAs (Zhou et al. 2000; Le Hir et al. 2001), the targeting in mammalian cells of mRNAs containing premature termination codons for nonsense-mediated mRNA decay (NMD) (Maquat 2004, 2005; Conti and Izaurralde 2005; Lejeune and Maquat 2005), proper subcytoplasmic localization in Drosophila of a translationally regulated mRNA necessary for early embryonic development (Hachet and Ephrussi 2001; Mohr et al. 2001; Palacios 2002; Palacios et al. 2004), and enhanced translational yields from spliced reporter mRNAs relative to otherwise identical mRNAs transcribed from cDNA constructs (Nott et al. 2003, 2004; Wiegand et al. 2003).

Structurally, the EJC consists of a stably bound core that is loaded onto the $5^{\prime}$ exon during the second step of splicing and that accompanies the spliced mRNA to the cytoplasm. This core serves as a binding platform for a host of more transiently interacting factors, which in turn interface with the various machineries involved in downstream mRNA metabolism (Tange et al. 2004). Intriguingly, stable interaction of the EJC with the region upstream of exon-exon junctions occurs without apparent dependence on RNA structure or sequence 
(Le Hir et al. 2000). To date, the only EJC factors that have been shown to interact directly with spliced mRNA at the EJC deposition site are human MLN51 and eIF4AIII (Shibuya et al. 2004; Ballut et al. 2005). MLN51 has no apparent homology to any other known RNA binding protein. In contrast, eIF4AIII (also known as DDX48, Nuk34, and hNMP 265) is a member of the DEAD-box family of RNA-dependent ATPases and exhibits remarkably high homology to the general translation initiation factors, eIF4AI and eIF4AII (67\% and $68 \%$ identity, respectively, between the human proteins) (Li et al. 1999). The latter proteins, which are functionally interchangeable, assist the small ribosomal subunit in finding the AUG translation initiation codon. In vitro, eIF4AI and eIF4AII have been shown to have RNA unwindase activity and so are widely believed to act in vivo as RNA helicases (Tanner and Linder 2001; Caruthers and McKay 2002; Rogers et al. 2002; Kapp and Lorsch 2004; Rocak and Linder 2004). Other DEAD-box family members have been shown to act as RNPases capable of removing bound proteins as they translocate along single-stranded RNA (Jankowsky et al. 2001; Linder et al. 2001; Schwer 2001; Fairman et al. 2004).

Because DEAD-box proteins generally interact with RNA in a sequence-independent manner, and crystal structures of related proteins indicate a nucleic acid binding site size of 8-10 nt (Kim et al. 1998; Tanner and Linder 2001), exactly the size of the EJC footprint on spliced mRNA (Le Hir et al. 2000), we proposed that eIF4AIII constitutes the main EJC anchoring factor on which the remainder of the EJC assembles. This identified eIF4AIII as the founding member of a new functional class of DEAD-box proteins that act as "RNA placeholders" or "molecular clothespins" instead of RNA helicases or RNPases (Shibuya et al. 2004). Whereas other DEAD-box proteins such as eIF4AI cycle through high and low affinity RNA binding states coupled to ATP hydrolysis (Lorsch and Herschlag 1998), eIF4AIII's association with spliced mRNA is remarkably stable.

Within the context of the EJC, eIF4AIII makes direct interactions with at least three other EJC core factors: MLN51, Y14, and Magoh (Palacios et al. 2004; Ballut et al. 2005; Tange et al. 2005). We recently found that when coexpressed in HeLa cells, eIF4AIII, MLN51, Y14, and Magoh can form a stable tetramer amenable to affinity purification (Tange et al. 2005). An analogous tetramer has been shown to assemble in vitro when recombinant versions of these four proteins are incubated together with ATP and single-stranded RNA (Ballut et al. 2005). This tetramer likely represents the minimal EJC core. Exactly how the individual components within this minimal core engage one another is currently unknown.

Here we describe the results of an extensive truncation and site-directed mutational analysis of human eIF4AIII. These studies were undertaken to begin the process of defining the sequences and structures in eIF4AIII that enable it to stably associate with spliced RNA in the context of the EJC core. We find that mutations in two of the canonical motifs defining the DEAD-box family (Ia and VI) disrupt numerous eIF4AIII activities and interactions, including NMD, in vitro EJC formation, and the in vivo interaction between eIF4AIII and Magoh. Similar results were obtained upon mutation of one of eight eIF4AIII-specific motifs. Another eIF4AIII-specific motif constitutes part of the binding site for MLN51. Finally, mutations in the canonical Walker A and B motifs that eliminate eIF4AIII's RNA-dependent ATPase activity in vitro are of no detectable consequence for EJC formation or NMD activation. We discuss the implications of these findings in the context of other recent publications as well as a new structural model for human eIF4AIII based on the known crystal structure of Saccharomyces cerevisiae eIF4AI.

\section{RESULTS}

\section{Sequence analysis of human eIF4AIII}

Initial identification of eIF4AIII as a close relative of eIF4AI and eIF4AII was based on comparison of human and mouse eIF4AI and eIF4AII to human, Xenopus laevis, Caenorhabditis elegans, Nicotiana plumbaginifolia, and Schizosaccharomyces pombe eIF4AIII orthologs (Li et al. 1999). We have now extended this analysis by identifying 19 different eIF4AIII orthologs from organisms spanning the animal, plant, and fungal kingdoms (Fig. 1; data not shown). As previously noted ( $\mathrm{Li}$ et al. 1999), eIF4AIII possesses all nine conserved motifs (Q, I, Ia, Ib, II, III, IV, V, VI) defining the DEAD-box family of RNA helicases (Fig. 1). Mutational studies of other DEAD-box family members, as well as analyses of several crystal structures, have revealed a number of functional roles for these canonical motifs. Motif Q forms the binding pocket for the adenylate base of ATP, while motifs I, II (also known as the Walker A and B motifs), III, and VI all interact with the ATP triphosphate. Motif II is particularly critical for ATP hydrolysis, while motifs III and VI link ATP binding and hydrolysis to interdomain movement and helicase activity. Motifs Ia, Ib, IV, and $\mathrm{V}$ all interact with the sugar-phosphate backbone of bound RNA (Tanner and Linder 2001; Caruthers and McKay 2002; Rogers et al. 2002; Tanner et al. 2003; Rocak and Linder 2004; Hernandez and Vazquez-Pianzola 2005).

In addition to the canonical DEAD-box helicase family motifs (Q-VI), eIF4AIII orthologs contain eight highly conserved motifs unique to eIF4AIII (Li et al. 1999), defined here as motifs A-H (Fig. 1). Importantly, eIF4AI and eIF4AII lack these sequences, suggesting that these eIF4AIII-specific motifs contribute to eIF4AIII's ability to act in a manner functionally distinct from eIF4AI and II.

\section{Structural modeling of elF4AIII}

Since the amino acid sequence of human eIF4AIII exhibits such high similarity to S. cerevisiae eIF4AI (65\% identity), a reasonably good model of human eIF4AIII (residues 35-411) 


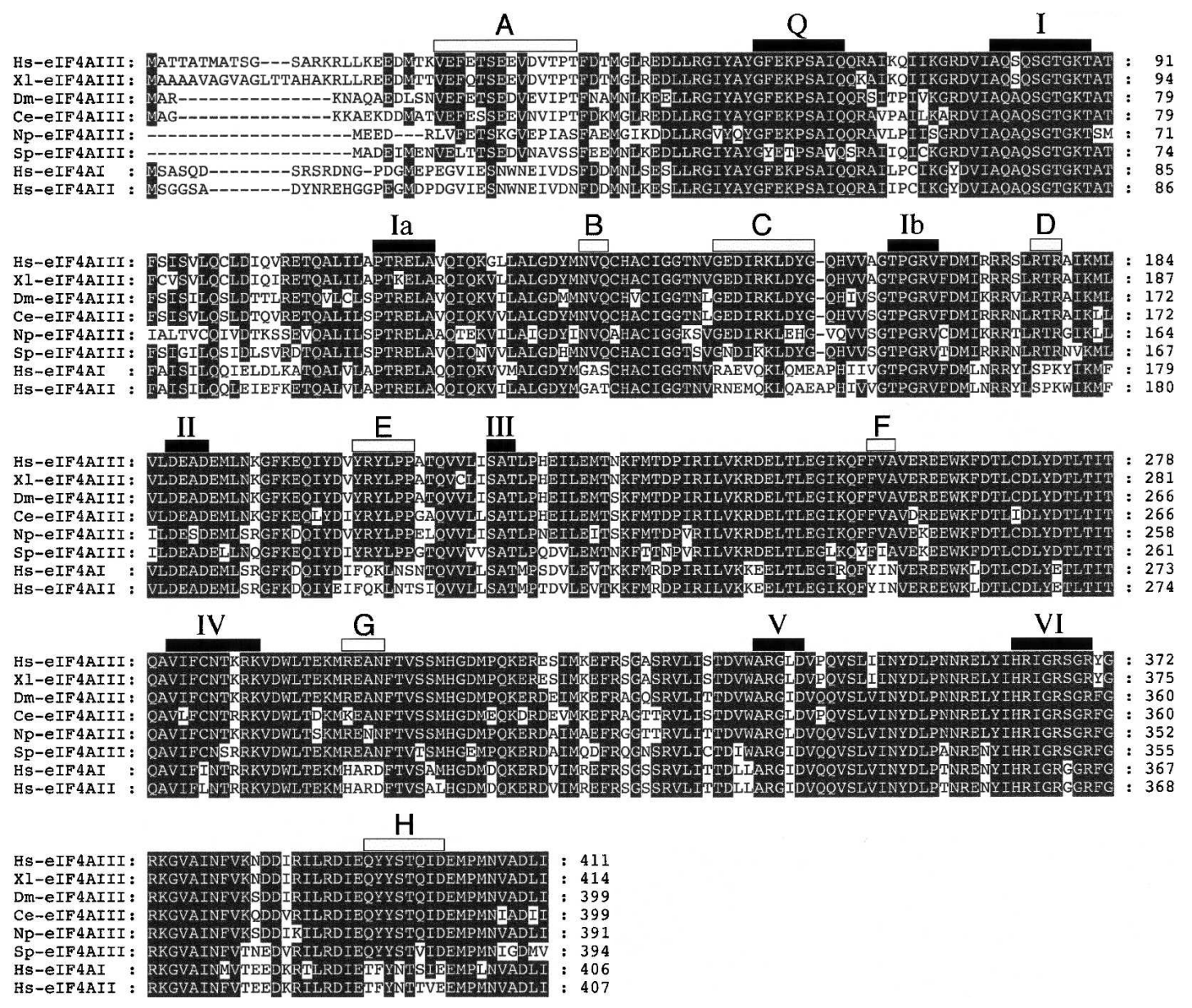

FIGURE 1. ClustalW amino acid sequence alignments of human eIF4AI, eIF4AII, and eIF4AIII (Hs-eIF4AIII, ENSG00000141543, accession \#P38919) and eIF4AIII homologs from Xenopus laevis (Xl-eIF4AIII, \#O42226), Drosophila melanogaster (Dm-eIF4AIII, \#CG7483), Caenorhabditis elegans (Ce-eIF4AIII, \#O44781), Nicotiana plumbaginifolia (Np-eIF4AIII, \#P41380), and Schizosaccharomyces pombe (Sp-eIF4AIII, \#Q10055). Identical amino acids are highlighted in black. Positions of eIF4A family consensus motifs (Q-VI) and eIF4AIII-specific motifs (A-H) are indicated by black and white bars, respectively.

could be constructed based on the known X-ray crystallographic structure of $S$. cerevisiae eIF4AI (residues 11-324) (PDB code 1FUU; Caruthers et al. 2000) using SwissModel (http://swissmodel.expasy.org//SWISS-MODEL.html; Schwede et al. 2003; Fig. 2). To assess the accuracy of the predicted secondary structure and the location of the canonical motifs, we aligned and visually compared the model with X-ray crystallographic structures of related DEAD-box proteins (Subramanya et al. 1996; Yao et al. 1997; Kim et al. 1998; Caruthers and McKay 2002). Like other family members, the eIF4AIII structure consists of two approximately equal sized domains (the $\mathrm{N}$ - and C-terminal domains), each comprising a seven parallel-stranded $\beta$-sheet sandwiched between $\alpha$ helices. A short linker connects the domains, giving the overall protein a "dumbbell" shape (Fig. 2). As the linker appears to allow for conformational flexibility between the domains in other structures (Caruthers et al. 2000), we clipped the sequence at eIF4AIII residue 244 and aligned each domain (N-terminal domain, residues 35-244; C-terminal domain, residues 245-411) independently with the corresponding region of the original eIF4AI structure.

As in other known DEAD-box protein structures, the canonical motifs (Q-VI) cluster in a large gap between the $\mathrm{N}$ - and C-terminal domains in our eIF4AIII model. The eight eIF4AIII-specific motifs (A-H) are primarily located on the solvent-accessible surface, forming four discrete patches (the $\mathrm{A}, \mathrm{B} / \mathrm{C} / \mathrm{D} / \mathrm{E}, \mathrm{G}$, and $\mathrm{F} / \mathrm{H}$ patches) in regions largely separate from the canonical motifs. Motif $\mathrm{A}$ is found in the N-terminal-most region, which differs significantly between eIF4AI and eIF4AIII and was somewhat disordered in the $S$. cerevisiae eIF4AI structure on which our model is based. Motifs B, C, D, and E coalesce to form an extended patch that caps one end of the $\mathrm{N}$-terminal domain. Motifs $\mathrm{B}, \mathrm{D}$, and $\mathrm{E}$ fall in loops linking the central $\beta$-strands with peripheral $\alpha$-helices, whereas motif $C$ falls on a variable helix outside the DEAD-box core (Caruthers et al. 2000). In the $\mathrm{C}$-terminal domain, motifs $\mathrm{F}$ and $\mathrm{H}$ form a single patch, while motif $\mathrm{G}$ forms a distinct isolated patch on the opposite 
A

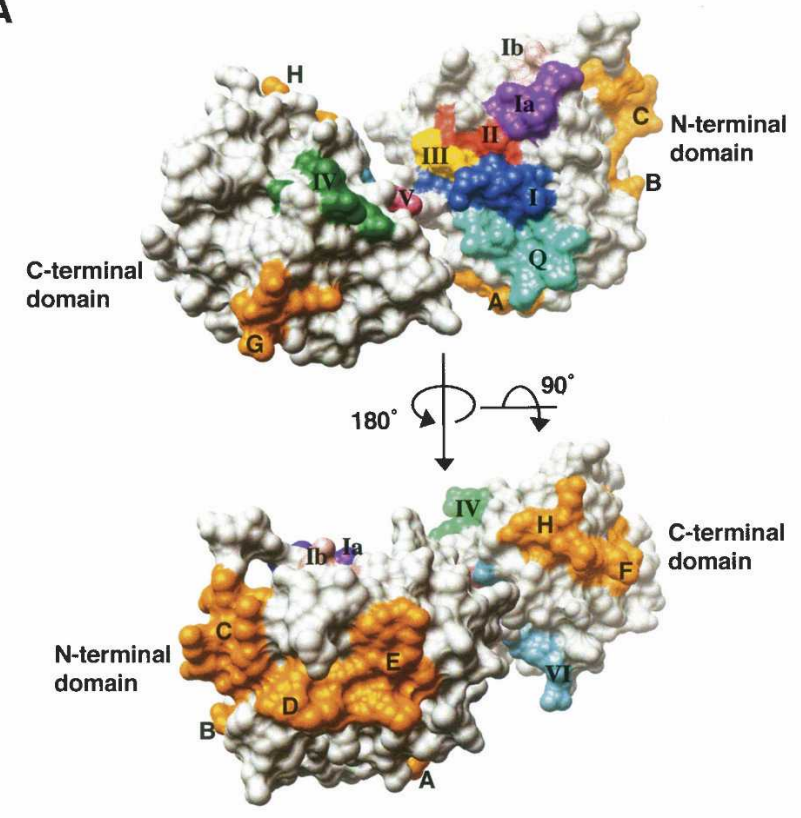

B

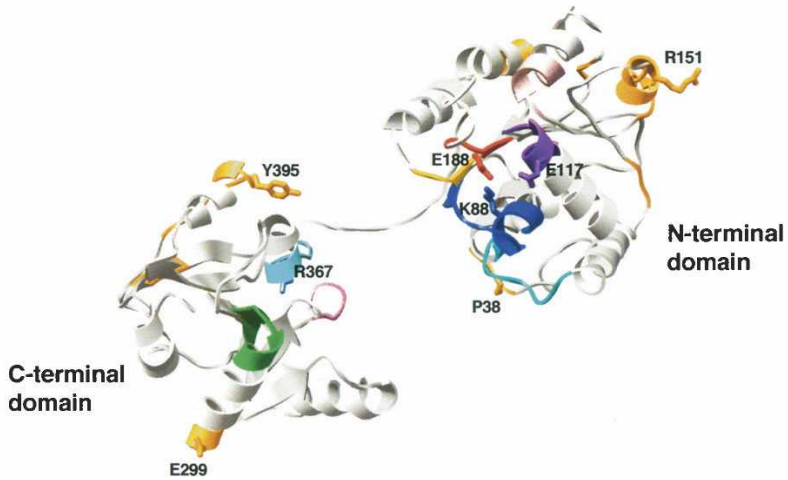

FIGURE 2. Structural model of residues 35-411 of human eIF4AIII based on the known X-ray crystal structure of Saccharomyces cerevisiae eIF4AI. The figure was generated using UCSF Chimera (Pettersen et al. 2004) and depicts the eIF4AIII molecular surface calculated with a 1.4$\AA$ radius probe (Sanner et al. 1996). Colors of canonical motifs are: motif Q (cyan), I (blue), Ia (purple), Ib (light pink), II (red), III (yellow), IV (green), V (pink), and VI (light blue). The eIF4AIIIspecific motifs are indicated in orange. Note that only a portion of motif A $\left({ }^{35} \mathrm{DVTPT}^{39}\right)$ is colored, as the remainder is not contained within the model. (B) Ribbon diagram in the same orientation as in $A$, top, with the same coloration scheme. A single side chain of one mutated residue in each motif is shown.

side. The distal positions of these four patches (the $\mathrm{A}, \mathrm{B} / \mathrm{C} / \mathrm{D} /$ $\mathrm{E}, \mathrm{G}$, and $\mathrm{F} / \mathrm{H}$ patches) suggest that they could serve as distinct binding sites for different interaction partners.

\section{Design of elF4AIII mutants}

To investigate the functionality of the canonical (Q-VI) and eIF4AIII-specific (A-H) motifs, we designed a number of site-specific mutations (Fig. 3). A lysine (K) to asparagine $(\mathrm{N})$ change in the Walker A motif (motif I: AQA QSGTGKT $\rightarrow$ AQAQSGTGNT) was previously shown to severely limit ATP binding by eIF4AI (Rozen et al. 1989; Pause and Sonenberg 1992). Similarly, mutation of eIF4AI motif Ia from PTRELA to PRRVAA is known to disrupt both its RNA unwindase and ATPase activities (Pause et al. 1994; Svitkin et al. 2001), as does mutation of the Walker B motif (motif II) from DEAD to DQAD (Pause and Sonenberg 1992; Pause et al. 1994; Svitkin et al. 2001). Finally, it has been reported that an arginine $(\mathrm{R})$ to glutamine $(\mathrm{Q})$ mutation in motif VI (HRIGRGGR $\rightarrow$ HRIGQGGR) significantly disrupts the ability of eIF4AI to bind RNA (Pause et al. 1993). On the basis of the strong effects of these specific mutations in eIF4AI, we used site-directed mutagenesis to create analogous mutant versions of eIF4AIII. In the case of motifs Ia and VI, we also created eIF4AIII versions containing fewer (Ia) or more (VI) mutations (i.e., PTRVLA, PRRVLA or HRIG QSGQ, HQIGQSGQ).

To study the possible roles of eIF4AIII-specific motifs, we selected motifs A $\left({ }^{26}\right.$ VEFETSEEVDVTPT $\left.{ }^{39}\right)$, C $\left({ }^{147}\right.$ GEDIR$\left.\mathrm{KLDYG}^{156}\right), \mathrm{G}\left({ }^{298} \mathrm{REAN}^{301}\right)$, and H $\left({ }^{394} \mathrm{QYYSTQID}^{401}\right)$, which our structural model (Fig. 2) predicted to each be part of distinct surfaces on eIF4AIII, and created the mutations indicated in Figure 3. We also constructed the six Nand C-terminal truncation mutants indicated. These truncations were designed to determine the extent to which the $\mathrm{N}$ - and C-terminal domains could act independently of one another, as well as the necessity of the $\mathrm{N}$-terminal extension in human eIF4AIII. A previous report had suggested that the sequence ${ }^{14}{ }^{\text {RKRLLLK }}{ }^{19}$ in the eIF4AIII-specific N-terminal extension (residues 1-22) not present in either eIF4AI or eIF4AII might serve as a nuclear localization signal (NLS) (Holzmann et al. 2000).

\section{Motifs la, VI, and $\mathrm{H}$ of elF4AIII contribute to NMD function in vivo}

It was previously shown that RNAi knockdown of eIF4AIII leads to a strong NMD defect in HeLa cells (Ferraiuolo et al. 2004; Palacios et al. 2004; Shibuya et al. 2004). To determine whether any of the mutations we created in eIF4AIII affected this NMD function, we tested each mutant protein for its ability to rescue the effect of endogenous eIF4AIII depletion. To do so, we employed a HeLa cell line (7C4) stably transfected with a version of a T-cell receptor beta (TCR- $\beta$ ) minigene containing a premature termination codon (PTC) in its second exon. This PTC+ mRNA serves as an extraordinarily efficient substrate for NMD (Muhlemann et al. 2001; Shibuya et al. 2004). As we previously demonstrated, depletion of endogenous eIF4AIII by RNAi against a sequence in the 3' UTR led to reappearance of the PTC-containing TCR$\beta$ mRNA (Fig. 4A,B, cf. lanes 1 and 2). When a mammalian expression vector encoding Flag-tagged wild-type eIF4AIII upstream of a different $3^{\prime}$ UTR was cotransfected with the same siRNA, NMD was largely restored (Fig. 4A,B, cf. lanes 2 and 3), confirming that the NMD defect was solely attributable to depletion of endogenous eIF4AIII. Cotransfection of 


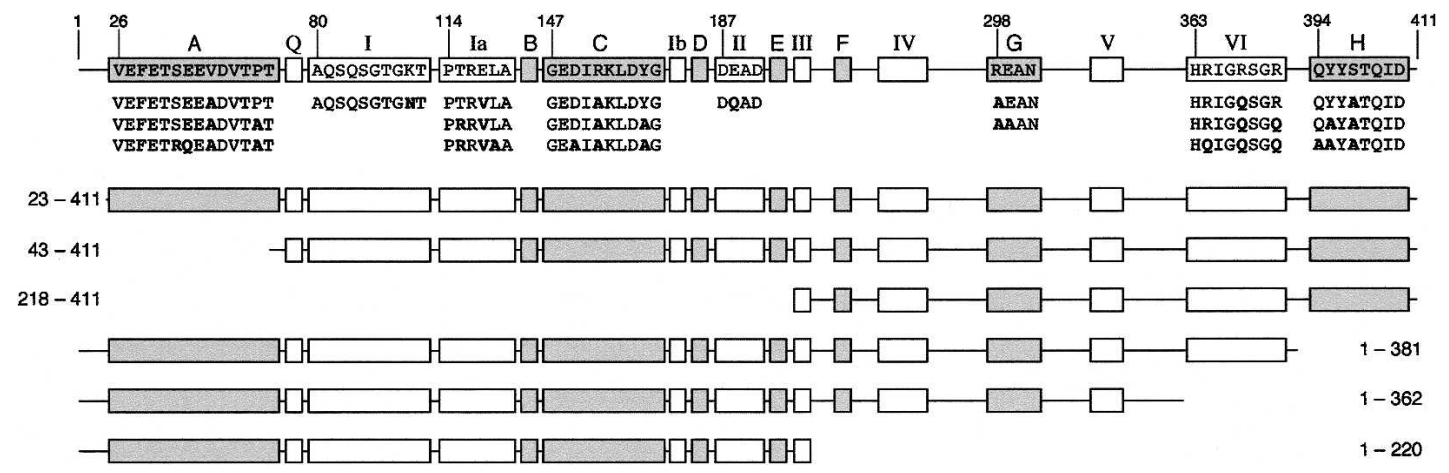

FIGURE 3. Schematic representation of eIF4AIII mutations. At the top is shown wild-type eIF4AIII with eIF4AIII-specific motifs and eIF4A family motifs (shaded and white boxes, respectively). Sequences below indicate site-specific mutations, with altered amino acids indicated as bold letters; each of the 19 mutant proteins examined contained mutations in one motif only. Truncation mutations are schematized below, with numbers indicating beginning and end of each using the full-length numbering system.

a vector expressing Flag-tagged bacterial alkaline phosphatase (BAP) served as a negative control (Fig. 4A,B, lane 25).

Among the truncation mutants, only eIF4AIII/23-411 was able to complement the NMD defect (Fig. 4A,B, cf. lanes 26 and 23-24,27-29), indicating that the first 22 amino acids are dispensable for eIF4AIII's function in
NMD. Cotransfection of any of the other truncation mutations along with the eIF4AIII siRNA was without consequence, suggesting that eIF4AIII function requires structural integrity of both its $\mathrm{N}$ - and C-terminal domains. In contrast to the truncations, most of the site-specific eIF4AIII mutants were able to rescue the NMD defect.

A

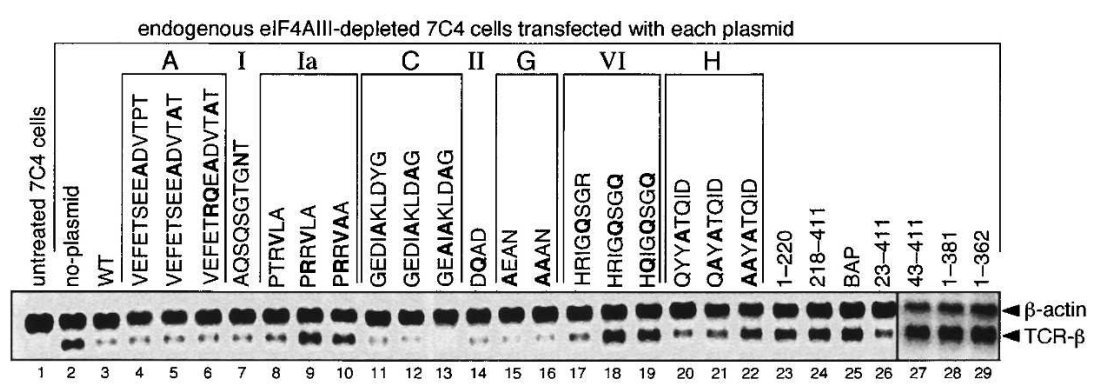

B

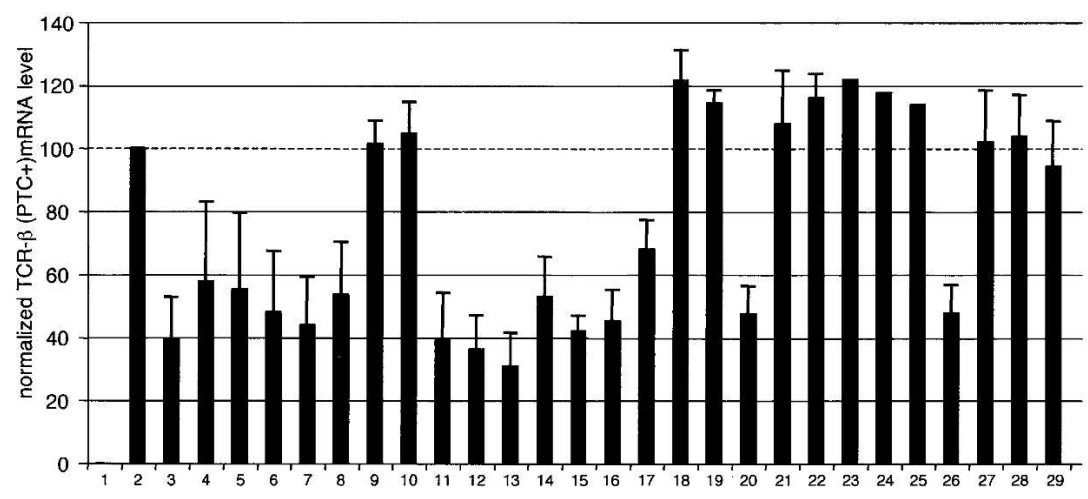

FIGURE 4. Rescue of NMD defect upon depletion of endogenous eIF4AIII by ectopic expression of wild-type and mutant Flag-tagged eIF4AIII constructs. RNAi-immune Flag-tagged eIF4AIII constructs were cotransfected with an siRNA against endogenous eIF4AIII into 7C4 HeLa cells, which contain a TCR- $\beta$ minigene substrate for NMD. (A) Northern blot of total RNA harvested from 7C4 cells cotransfected with eIF4AIII siRNA and each RNAi-immune eIF4AIII expression vector (lanes 3-29). Untreated cells, cells treated with siRNA only, and cells cotransfected with FlagBAP served as controls (lanes $1,2,25$, respectively). Blots were probed with radiolabeled TCR- $\beta$ and $\beta$-actin control cDNAs. (B) PTC-containing TCR- $\beta$ mRNA levels were normalized to $\beta$-actin mRNA signals and then to TCR- $\beta$ levels in eIF4AIII-depleted cells containing no cotransfected plasmid (lane 2; arbitrarily set to 100). Except for bars 23-25, which are results of a single experiment, each bar represents the mean of three independent experiments; error bars indicate standard deviations. Bar numbers in $B$ correspond to lanes in $A$. 
Surprisingly, this set included mutations in the Walker A and B motifs (AQSQSGTGNT and DQAD) that are not only essential for eIF4AI function but also eliminate eIF4AIII's RNA-stimulated ATPase activity (see below). The only site-specific mutant versions unable to rescue the NMD defect were those containing multiple mutations in motifs Ia, VI, or H; in these cases, levels of PTC+ TCR$\beta$ mRNA were similar to that obtained upon endogenous eIF4AIII depletion alone (Fig. 4A,B, lanes 9-10,1819,21-22).

\section{Motifs la, $\mathrm{VI}$, and $\mathrm{H}$ are required for the interaction of elF4AIII with spliced mRNA}

We next examined whether any of the mutations affected eIF4AIII's association with spliced mRNA. To do so, we performed in vitro splicing assays containing recombinant C-terminal GST-tagged eIF4AIII protein and assessed whether any of the mutations affected the ability of eIF4AIII-GST to precipitate spliced mRNA. Briefly, purified recombinant eIF4AIII-GST proteins were combined with

${ }^{32}$ P-labeled AdML pre-mRNA substrate in in vitro splicing reactions containing HeLa nuclear extract. The recombinant eIF4AIII-GST was added to an $\sim 20$-fold excess over endogenous eIF4AIII, as judged by Western blotting (data not shown). After incubation under splicing conditions for sufficient time to generate spliced products, GST pull-down assays were performed. Under these conditions, wild-type eIF4AIII-GST efficiently precipitated the spliced exon product (Fig. 5, lane 2), and to a lesser extent, splicing intermediates (i.e., the free $5^{\prime}$ exon and lariat $3^{\prime}$ exon). Precipitation of splicing intermediates is consistent with eIF4AIII being a known component of $\mathrm{C}$ complex spliceo-

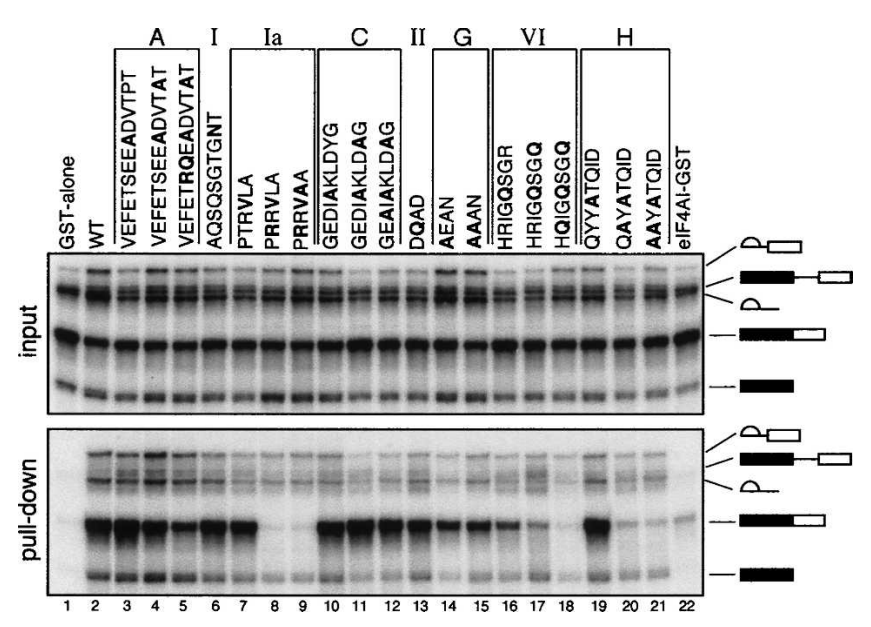

FIGURE 5. In vitro splicing and pull-down assays with GST-tagged eIF4AIII mutants. (Top panel) Splicing reactions prior to GST pulldown; (bottom panel) splicing reactions after GST pull-down. RNAs were separated on $15 \%$ denaturing polyacrylamide gels. Splicing substrate, intermediates, and products are represented to the right. GST alone and eIF4AI-GST served as negative controls. somes (Jurica and Moore 2003; Jurica et al. 2004). GST alone and eIF4AI-GST served as negative controls-neither protein efficiently precipitated either splicing intermediates or the spliced exon product (Fig. 5, lanes 1,22).

Paralleling their effects on NMD in vivo (Fig. 4), mutations in motifs Ia, VI, or H negatively impacted the ability of eIF4AIII to stably interact with spliced exons in vitro: As the number of mutations in motifs Ia, VI, or $\mathrm{H}$ increased, the ability of the mutant protein to precipitate the spliced exons decreased (Fig. 5, lanes 8-9,17-18,20-21). All other site-specific mutant variants of eIF4AIII-GST, including those carrying mutations in the Walker $\mathrm{A}$ and $\mathrm{B}$ motifs (motifs I and II), precipitated the spliced exon product with efficiencies similar to wild type. Thus none of these latter mutations affected the abilities of eIF4AIII to be loaded onto or remain stably associated with the spliced mRNA.

In contrast to the spliced exon product, all mutant eIF4AIII-GST proteins coprecipitated splicing intermediates (lariat-3' exon and free $5^{\prime}$ exon) with efficiencies indistinguishable from wild-type eIF4AIII-GST (Fig. 5, lanes 2-21). This indicates that none of the site-specific mutations tested here interfere with the ability of eIF4AIII to be incorporated into C complex spliceosomes. Therefore, recruitment of eIF4AIII to the spliceosome must occur by way of separate interactions from those required for it to stably associate with spliced mRNA.

\section{ATPase activities of elF4AIII mutants}

Despite their debilitating effects on eIF4AI function (Rozen et al. 1989; Pause and Sonenberg 1992; Pause et al. 1994; Svitkin et al. 2001), point mutations in the Walker A and B motifs were inconsequential for eIF4AIII's abilities to rescue NMD in vivo (Fig. 4) or associate with spliced mRNA in vitro (Fig. 5). To confirm that the mutations we tested did affect eIF4AIII's ability to hydrolyze ATP, we performed in vitro ATPase assays in the presence or absence of RNA (Fig. 6). For these experiments, the wild-type and mutant eIF4AIII-GST fusion proteins described above were additionally purified on a heparin column to minimize possible contamination by endogenous Escherichia coli ATPases (see Materials and Methods).

Wild-type eIF4AIII-GST exhibited higher ATPase activity in the presence of RNA than in its absence (Fig. 6A,B), indicating that this fusion protein retained the RNA-dependent ATPase activity previously observed for untagged eIF4AIII ( $\mathrm{Li}$ et al. 1999). In contrast, the motif I (AQSQSGTGNT) and II (DQAD) mutants exhibited no difference in ATPase activity plus or minus RNA; all rates for these mutants were similar to that exhibited by the wildtype protein in the absence of RNA. At this point we cannot distinguish whether the RNA-independent ATPase activity observed for both the wild-type and mutant proteins is attributable to eIF4AIII-GST or residual contaminating 
A

\begin{tabular}{|c|c|c|c|c|c|c|c|c|c|c|c|c|c|c|c|c|c|c|c|c|}
\hline \multicolumn{10}{|c|}{ WT } & \multicolumn{10}{|c|}{ DQAD } & \multirow[b]{3}{*}{ Time (hr) } \\
\hline & & RNA & & & & & $\mathrm{RN}$ & & & & & $\mathrm{RN}$ & & & & & $\mathrm{RN}$ & & & \\
\hline 0 & 0.5 & 1 & 2 & 3 & 0 & 0.5 & 1 & 2 & 3 & 0 & 0.5 & 1 & 2 & 3 & 0 & 0.5 & 1 & 2 & 3 & \\
\hline & & 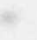 & & - & & - & & & & & $\theta$ & & $\bullet$ & - & & 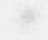 & $=$ & - & • & $\leftarrow^{32} \mathrm{Pi}$ \\
\hline
\end{tabular}

B

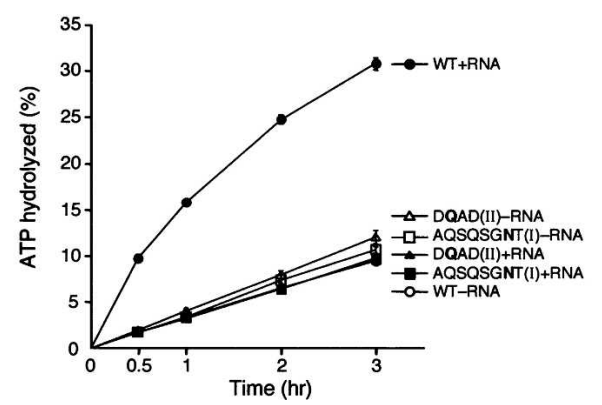

FIGURE 6. ATPase activity of eIF4AIII-GST (wild type and mutants) in the presence or absence of RNA. (A) Representative autoradiogram showing the release of ${ }^{32} \mathrm{Pi}$. (B) Quantification of ATPase reactions, with each point representing the average of three independent experiments.

E. coli ATPases (Tanner et al. 2003). Nevertheless, these data do confirm that, as expected from previous mutational analyses of eIF4AI, mutations in the Walker A and B motifs of eIF4AIII negatively impact its ability to hydrolyze ATP, at least in the presence of RNA.

\section{Identification of sequences required for in vivo interaction with Magoh}

We next examined which regions of eIF4AIII are necessary for specific interactions with other EJC core components. Immunoprecipitation assays previously showed that eIF4AIII stably associates in vivo with the EJC component Magoh (Chan et al. 2004; Shibuya et al. 2004). To determine whether any of the mutations affected this interaction, similar immunoprecipitation assays were performed using Flag-tagged versions of the eIF4AIII mutants. Human HEK293T cell extracts transiently expressing individual Flag-tagged eIF4AIII mutants were subjected to immunoprecipitation with anti-Flag antibody, and coimmunoprecipitated proteins were resolved by SDS-PAGE and then analyzed by
Western blotting with anti-Magoh antibody (Fig. 7).

This analysis revealed that mutations in motifs $\mathrm{Ia}, \mathrm{VI}$, and $\mathrm{H}$ significantly disrupted eIF4AIII's ability to interact stably with Magoh (Fig. 7, lanes 7-8,1517,19-20). In motifs Ia and $\mathrm{H}$, the eIF4AIII-Magoh interaction was only disrupted when multiple amino acids were mutated. Other site-specific mutations, including those in the Walker A and B motifs (motifs I and II), had no apparent effect on the interaction with Magoh. Among the truncation mutants, only the one lacking the first 22 amino acids (eIF4AIII/23-411) exhibited any detectable Magoh association (Fig. 7, lanes 21-24,26,27). Thus the in vivo association between eIF4AIII and Magoh was affected by essentially the same set of mutations as were eIF4AIII's NMD and EJC formation activities.

\section{Identification of the MLN51 interaction region}

A previous study showed that eIF4AIII interacts with in vitro-translated fulllength MLN51 in reticulocyte lysate. The $\mathrm{N}$ terminus of Barentsz (the Drosophila homolog of MLN51) also interacts with Drosophila eIF4AIII in a two-hybrid assay (Palacios et al. 2004). To test whether any of our eIF4AIII mutants disrupted this interaction, we performed immunoprecipita-

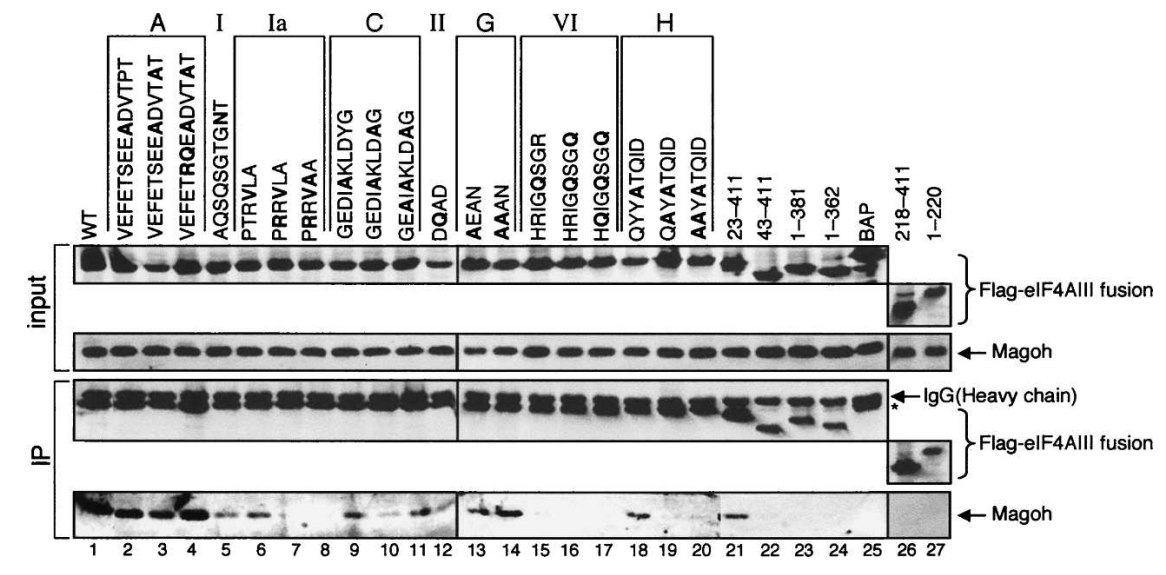

FIGURE 7. Coimmunoprecipitation analysis of Flag-tagged eIF4AIII constructs with endogenous Magoh. Total protein extracts from HEK293T cells transfected with wild type, mutants, or truncations of eIF4AIII were treated with RNaseA, immunoprecipitated with anti-Flag, and analyzed by Western blotting using anti-Flag and anti-Magoh antibodies. Flag-tagged BAP served as a negative control. The asterisk indicates the positions of Flag-BAP and full-length Flag-tagged eIF4AIII, which both migrated just below the IgG heavy chain band. Inputs represent $2.5 \%$ of total protein extract used for immunoprecipitation. 
tions from extracts of HEK293T cells transiently transfected with each GFP-tagged eIF4AIII construct plus Flag-tagged full-length MLN51 (Fig. 8A-C). Immunoprecipitation with anti-Flag antibody followed by Western blotting with antiGFP and anti-Magoh antibody showed that Flag-MLN51 interacts in vivo with wild-type GFP-eIF4AIII as well as endogenous Magoh (Fig. 8A, lane 3). As a negative control, we showed that neither GFP-eIF4AIII nor Magoh were coimmunoprecipitated with Flag-BAP (Fig. 8A, lane 4).

Neither the N-nor C-terminal half of eIF4AIII (1-220 and 218-411, respectively) exhibited any association with FlagMLN51 (Fig. 8B, lanes 5,6). Similar results were obtained with the 43-411 truncation (Fig. 8C, lane 8 ). In contrast, the 23-411, 1-381, and 1-362 truncations all exhibited significant coprecipitation with Flag-MLN51 (Fig. 8C, lanes 7,9,10). Taken together these results suggest that the MLN51 binding region on eIF4AIII maps between residues 23 and 362 .

To locate the MLN51 binding site more precisely (Fig. 8D,E), we separately expressed and purified from $E$. coli wild-type and mutant versions of eIF4AIII as C-terminal GST-fusions (eIF4AIII-GST) as well as the N-terminal region (amino acids 1-400) of MLN51 carrying a $\mathrm{His}_{6}$-tag at its $\mathrm{C}$ terminus (N-term400 MLN51-His 6 ). Recombinant N-term400 MLN51$\mathrm{His}_{6}$ also contained a heart muscle kinase (HMK) phosphorylation site at its $\mathrm{N}$ terminus, permitting radioactive labeling of this protein. GST pull-down assays were carried out as described in Materials and Methods and bound proteins separated by SDS-PAGE. The gel was first stained with Coomassie to verify that each eIF4AIII-GST fusion protein was efficiently recovered, and then $\mathrm{N}$ term400 MLN51-His 6 was detected by phosphorimaging of the radioactive phosphate. Using this strategy we found that wild-type eIF4AIII-GST efficiently precipitated N-term 400 MLN51-His ${ }_{6}$ from an in vitro binding reaction (Fig. 8D, lane 2), whereas GST-alone and eIF4AI-GST did not (Fig. 8D, lanes 1,11). Consistent with the previous two-hybrid results (Palacios et al. 2004), our data indicate that eIF4AIII interacts directly with the N-terminal 400 amino acids of MLN51.

The majority of the eIF4AIIIGST site-specific mutant versions were able to precipitate N-term 400

A

B

C
MLN51-His $_{6}$ as efficiently as wild-type eIF4AIII-GST. However, mutations in eIF4AIII-specific motif C $\left({ }^{147}\right.$ GEDIRKL$\mathrm{DYG}^{156}$ ) interfered with this interaction in proportion to the number of mutations present, with three changes leading to full disruption (Fig. 8D, lane 6, E, lanes 3-5). Thus, the eIF4AIII-specific motif $\mathrm{C}$ is required for the direct interaction of eIF4AIII with the $\mathrm{N}$ terminus of MLN51 in vitro.

Although motif $\mathrm{C}$ mutations disrupted interaction between eIF4AIII-GST and the N-terminal half of MLN51 in vitro, they were of little or no consequence in the other assays described above (see Figs. 4, 5, and 7). This suggested that in the context of full-length MLN51, contacts in motif $\mathrm{C}$ are unnecessary for the eIF4AIII:MLN51 interaction. To examine this possibility further, we coexpressed GFP-tagged versions of all of the site-specific mutations in eIF4AIII with full-length Flag-tagged MLN51 in HEK293T cells (Fig. 8F). Immunoprecipitation with anti-Flag antibodies followed by
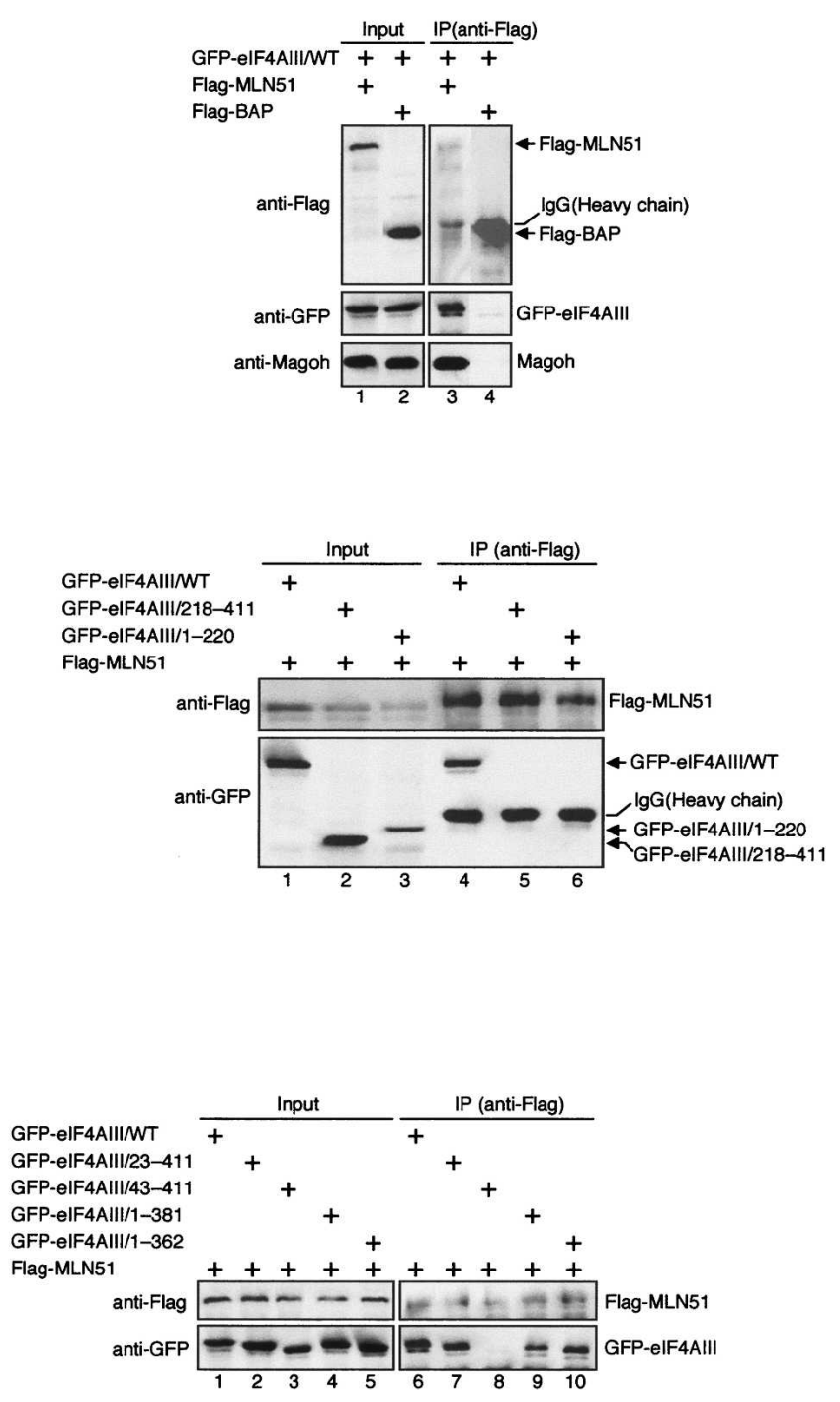

FIGURE 8. (Continued on next page) 
Western blotting with anti-GFP confirmed that all of the site-specific mutant versions of eIF4AIII, including those containing mutations in motif $\mathrm{C}$ (Fig. $8 \mathrm{~F}$, lane 14), are capable of stable interaction with full-length MLN51 in vivo.

\section{Subcellular localization of GFP-tagged eIF4AIII mutants}

When expressed in HeLa cells, GFP-tagged eIF4AIII accumulates in nuclear speckles that colocalize with splicing factor SC35 (Palacios et al. 2004; Shibuya et al. 2004). To test whether any of the eIF4AIII mutations affected this localization pattern, we assessed the subcellular localization patterns of GFP-tagged versions of each eIF4AIII mutant protein in transiently transfected HeLa cells. With two exceptions, all site-specific mutants exhibited the same speckled nuclear localization pattern as wild-type eIF4AIII

D

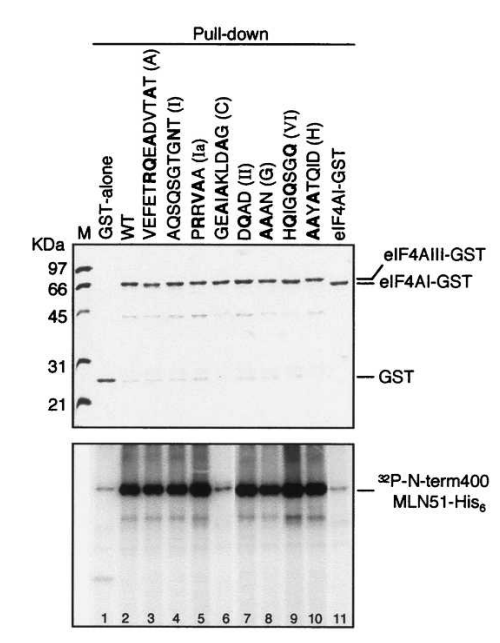

$\mathbf{F}$

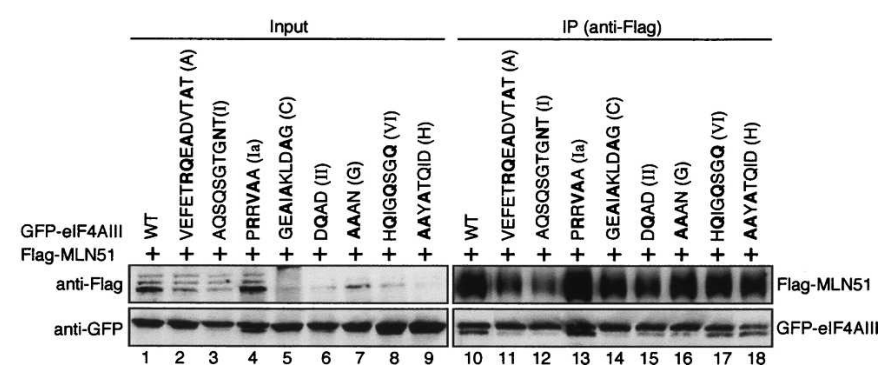

FIGURE 8. Interaction between eIF4AIII and MLN51 in vivo and in vitro. $(A-C, F)$ Coimmunoprecipitation analysis of Flag-tagged full-length MLN51 with GFP-tagged eIF4AIII mutants in vivo. Total protein extracts from HEK293T cells cotransfected with Flag-tagged full-length MLN51 and GFP-tagged eIF4AIII mutants, treated with RNaseA, immunoprecipitated with anti-Flag and analyzed by Western blot using anti-Flag, anti-GFP, and anti-Magoh antibodies. Lysates from cells expressing Flag-BAP were used as controls. Inputs represent $2 \%$ of total protein extract used for immunoprecipitation. ( $D, E)$ GST pull-down assay with recombinant eIF4AIIIGST mutants and ${ }^{32} \mathrm{P}$-labeled N-terminal half MLN51-His ${ }_{6}$ in vitro. Top and bottom panels correspond to Coomassie stained images and phosphorimages, respectively, of the same gel.
(Fig. 9; data not shown). The exceptions were mutants containing multiple mutations in motif Ia-the PRRVLA and PRRVAA mutant proteins exhibited significant nucleoar accumulation in addition to the typical nucleoplasmic and nuclear speckle signals (Fig. 9). Among the truncation mutants, only eIF4AIII/23-411 exhibited a wild-type locaization pattern (Fig. 9); the other five truncations exhibited variable localization patterns that were not readily interpre(data not shown). Thus, consistent with residues 1-22 net being well conserved across species (Fig. 1), our results indicate that this region, including the ${ }^{14} \mathrm{RKRLLK}^{19}$, is not necessary for nuclear localization.

\section{DISCUSSION}

This article reports results of an extensive mutational analysis of human eIF4AIII. Site-directed mutations were designed to test the functionality of several eIF4AIII specific motifs as well as motifs shared with other members of the DEAD-box family of RNA helicases. To better interpret the results of these studies, we created a structural model of human eIF4AIII based on the known Xray crystal structure of yeast eIF4AI. This model, coupled with our functional analysis of the mutant proteins, provides significant insight into this fascinating protein at the center of the EJC core.

\section{Motifs la, $\mathrm{VI}$, and $\mathrm{H}$ are crucial for EJC formation and NMD}

Mutations in canonical motifs Ia and VI, as well as eIF4AIII-specific motif $\mathrm{H}$, had similar consequences both in vivo and in vitro. That is, site-specific mutations in all three motifs disrupted the ability of ectopically expressed eIF4AIII to complement the NMD defect produced upon RNAi depletion of endogenous eIF4AIII (Fig. 4), in vitro EJC formation (Fig. 5), and the in vivo interaction between eIF4AIII and Magoh (Fig. 7).

In X-ray crystal structures of related helicases bound to oligonucleotides, motif Ia interacts with the sugar-phosphate backbone of RNA or DNA (Tanner and Linder 2001; Caruthers and McKay 2002). In eIF4AI, mutation of motif Ia to PRRVAA alters both helicase and ATPase activities (Svitkin et al. 2001), linking enzyme activity to oligonucleotide binding. In the same crystal 


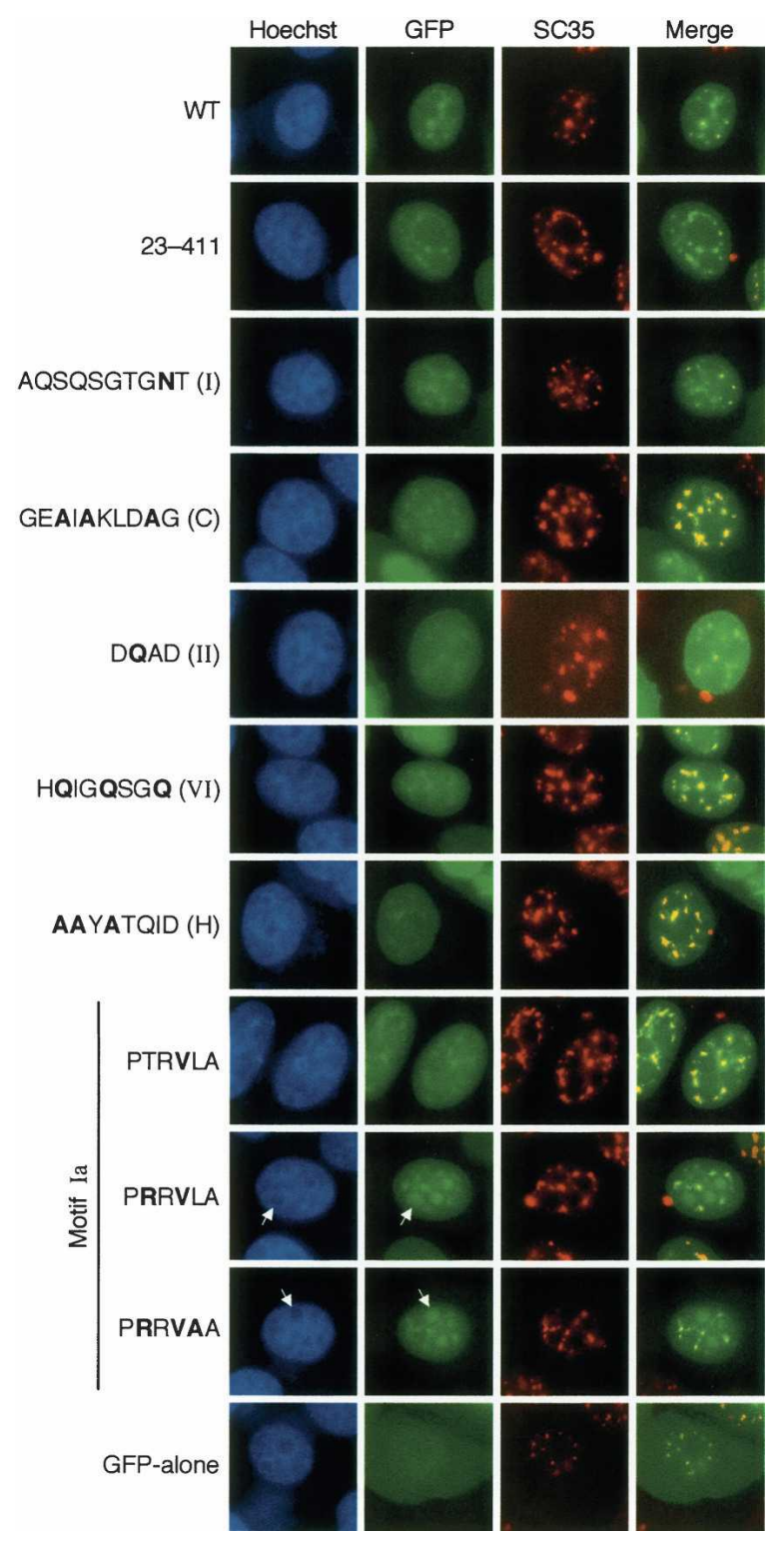

FIGURE 9. Immunofluorescence analysis of HeLa cells transiently transfected with pEGFP-eIF4AIII constructs. Cells were fixed, permeabilized, and labeled with anti-SC35 antibody (red). Nuclei were counterstained with Hoechst dye (blue); arrows indicate nucleoli.

structures, motif VI is positioned away from the bound nucleic acid, directly interacting instead with the $\gamma$-phosphate of ATP via its central arginine (Tanner and Linder 2001; Caruthers and McKay 2002). Nonetheless, the HRIGQxxR mutation in eIF4AI significantly disrupts the ability of that protein to bind RNA as well as hydrolyze ATP (Pause et al. 1993). This motif likely links ATP binding to a conformational change between the $\mathrm{N}$ - and C-terminal domains that increases the protein's affinity for RNA in the ATP-bound state (Tanner and Linder 2001; Caruthers and McKay 2002). In this way, both motifs Ia and VI contribute to protein-oligonucletide binding. We propose that in eIF4AIII, defects in either motif Ia or VI cause decreased affinity for RNA, thereby destabilizing the EJC and disrupting its function in NMD. Since eIF4AIII mutations expected to disrupt RNA binding also disrupted its stable association with Magoh (Fig. 7), a corollary of this proposal is that stable interaction between eIF4AIII and Magoh occurs only within the context of a properly assembled EJC. This idea is consistent with recent data from Ballut et al. (2005), showing that recombinant eIF4AIII and Magoh stably associate in vitro only under conditions that promote formation of the minimal tetrameric EJC core.

In contrast to the central, well-characterized canonical helicase motifs, eIF4AIII-specific motif $\mathrm{H}$ maps far from the active site in our structural model (Fig. 2). How is it that mutations in motif $\mathrm{H}$ have such similar consequences to mutations in motifs Ia and VI? One possibility is that the F/ $\mathrm{H}$ patch constitutes a novel RNA binding site not seen in related proteins. However, given the lack of any positive charge in the $\mathrm{F} / \mathrm{H}$ patch and its high hydrophobicity, this seems unlikely. An alternate explanation is that this region forms part of a protein:protein interface that facilitates EJC deposition during splicing, stabilizes eIF4AIII binding to spliced mRNA, and/or ensures overall structural integrity of the EJC.

We recently found that when coexpressed in HeLa cells, eIF4AIII, Magoh, Y14, and MLN51 can form a stable tetramer that likely represents the minimal EJC core (Tange et al. 2005). An analogous tetramer was recently shown to assemble in vitro when recombinant versions of these four proteins were incubated together with ATP and singlestranded RNA (Ballut et al. 2005). Given these results, it is tempting to speculate that eIF4AIII motif $\mathrm{H}$ may represent an interaction surface for one of the other core factors. This factor is likely not MLN51, because MLN51 associates with eIF4AIII versions containing mutations in motif $\mathrm{H}$ (Fig. 8F, lane 18) as well as with eIF4AIII C-terminal truncations (1381 and 1-362) lacking motif $\mathrm{H}$ all together (Fig. 8C, lanes 9,10). On the other hand, Magoh failed to interact with any of these mutants (Fig. 7). These results suggest that motif $\mathrm{H}$ may constitute part of the binding site for Magoh or its dimerization partner Y14. As with mutations in motifs Ia or VI, altering motif $\mathrm{H}$ could disrupt a key contact required for EJC formation or stability, which would in turn prevent stable association of eIF4AIII with spliced mRNA and disrupt its function in NMD. Clearly further experimentation will be required to test this hypothesis.

\section{Motif C constitutes part but not all of the MLN51 binding site}

Motif $\mathrm{C}$ was found to be important for the interaction between eIF4AIII and the N-terminal half of MLN51 in vitro (Fig. 8D,E). Nevertheless, other experiments showed that in vivo NMD function (Fig. 4) and in vitro and in vivo EJC formation (as assessed by spliced exon product [Fig. 5] 
and Magoh [Fig. 7] coprecipitation, respectively) were unaffected by the same motif $\mathrm{C}$ mutations. Further, full-length MLN51 retains its ability to interact with motif $\mathrm{C}$ mutants (Fig. 8F, lane 14). Thus, in the context of the whole EJC, these mutations are likely compensated by other interactions between full-length MLN51 and other eIF4AIII motifs. Consistent with this idea, direct interaction of eIF4AIII with MLN51 has been shown to be greatly enhanced by the presence of the Magoh:Y14 heterodimer (Palacios et al. 2004; Ballut et al. 2005). Thus, interactions between full-length MLN51 and eIF4AIII motif C mutants may be stabilized by interactions with Magoh and/or its binding partner Y14.

\section{Mutations in the Walker A and B motifs are benign for NMD and EJC formation}

Canonical motifs I and II (also known as the Walker A and B NTP-binding motifs) are essential for the in vitro ATPase and helicase activities of eIF4AI and other DEAD-box family members (Rozen et al. 1989; Pause and Sonenberg 1992; Pause et al. 1994; Svitkin et al. 2001). Structural analysis of eIF4AI and related proteins has revealed that the amino group of the penultimate lysine in motif I (AQAQSGTGKT) interacts with the phosphates of MgATP and MgADP, while the hydroxyl of the terminal threonine (AQAQSGTGKT; serine in some proteins) coordinates the active site $\mathrm{Mg}^{2+}$ ion. The first aspartate in motif II (DEAD) provides an additional ligand for the $\mathrm{Mg}^{2+}$ ion, while the glutamate (DEAD) is the presumed catalytic base for ATP hydrolysis (Tanner and Linder 2001; Caruthers and McKay 2002). In eIF4AI, mutational analyses showed that a lysine $(\mathrm{K})$ to asparagine $(\mathrm{N})$ change in motif I severely inhibits both ATP binding and ATP hydrolysis in vitro, while a glutamic acid (E) to glutamine (Q) mutation in motif II abrogates ATP hydrolysis, but ATP binding activity is slightly retained (Rozen et al. 1989; Pause and Sonenberg 1992; Pause et al. 1994; Svitkin et al. 2001).

With eIF4AIII-GST fusion proteins, we observed that the motif I AQSQSGTGNT and motif II DQAD mutations both eliminated the RNA-dependent ATPase activity of eIF4AIIIGST (Fig. 6). Nonetheless, these same mutations were of no negative consequence for several other eIF4AIII activities, including the abilities of the mutant proteins to rescue NMD upon RNAi knockdown of endogenous eIF4AIII (Fig. 4), associate with spliced exons in vitro (Fig. 5), and associate with Magoh in vivo (Fig. 7). Taken together, these results indicate that the AQSQSGTGNT and DQAD mutations have little or no effect on eIF4AIII's ability to be incorporated into the EJC in vitro or in vivo. Similar results were recently reported for in vitro assembly of the tetrameric EJC core: A different mutation in motif I (AQSQSGTGAT) that also abrogated eIF4AIII's RNA-dependent ATPase activity had no adverse effect on tetramer formation. Further, both ATP and the nonhydrolyzable analog AMP-PNP supported core assembly with wild-type eIF4AIII. Additional data clearly showed that stable association of the EJC core with RNA is maintained through Y14:Magoh-mediated inhibition of eIF4AIII's ATPase activity (Ballut et al. 2005).

If ATP hydrolysis is not required for EJC formation or stability, why are motifs I and II so highly conserved in eIF4AIII (Fig. 1)? As stated above, eIF4AIII has been shown to exhibit RNA-dependent ATPase and ATP-dependent RNA unwinding activities in vitro. Also like eIF4AI, efficient RNA unwinding by eIF4AIII is significantly enhanced by the processivity factor eIF4B. Further, eIF4AIII additionally interacts with the general translation initiation factor eIF4G. Unlike eIF4AI, however, recombinant eIF4AIII was found to inhibit rather than stimulate in vitro translation reactions. For these reasons, eIF4AIII has been proposed to be a negative regulator of translation (Li et al. 1999). Such a role has also been proposed for eIF4AIII in developmental control of translation in X. laevis, where eIF4AIII overexpression induced epidermis formation by dissociated cells that would otherwise have adopted a neural fate (Weinstein et al. 1997). Thus, while residues in eIF4AIII's ATPase motifs are apparently not required for EJC formation and its role in NMD, they may be important for eIF4AIII's other presumed function as a translational regulator.

\section{EJC formation is not required for elF4AIII recruitment to spliceosomes}

All site-specific mutant versions of eIF4AIII-GST tested here coprecipitated splicing intermediates from in vitro splicing reactions with the same efficiency as wild-type eIF4AIII-GST (Fig. 5). Thus none of the mutations we examined appeared to disrupt initial recruitment of eIF4AIII to the spliceosome. These in vitro observations were consistent with the in vivo localization data, which showed that all site-specific eIF4AIII mutants colocalized with the splicing factor SC35 in nuclear speckles (Fig. 9). Interestingly, motif Ia mutants also exhibited some nucleolar accumulation. To date, we do not have a definitive explanation for why motif Ia mutants are found in the nucleolus. However, in Arabidopsis thaliana, the putative eIF4AIII ortholog and other EJC components also reportedly localize to the nucleolus (Pendle et al. 2005). This observation opens the possibility that eIF4AIII and/or other EJC components may have additional functions related to pre-rRNA processing and/or ribosome assembly.

\section{The $\mathrm{N}$-terminal 22 amino acids are unnecessary for human elF4AIII function}

Even though the eIF4AIII-specific motif ${ }^{14}$ RKRLLK ${ }^{19}$ was predicted to be a nuclear localization signal (NLS) (Holzmann et al. 2000), the truncation mutant (eIF4AIII/23-411) lacking all 22 amino acids at the $\mathrm{N}$ terminus exhibited a subcellular localization pattern similar to that of wild-type eIF4AIII (Fig. 9), could make stable associations with 
Magoh and MLN51 in vivo (Figs. 7, 8), and could rescue the NMD defect triggered by depletion of endogenous eIF4AIII (Fig. 4). Additionally, another group recently reported that eIF4AIII lacking the $20 \mathrm{~N}$-terminal amino acids can associate with Y14 and Magoh and induce NMD in a tethering assay (Gehring et al. 2005). Moreover, eIF4AIII site-specific mutants in which the positive charged amino acids lysine $(\mathrm{K})$ and arginine $(\mathrm{R})$ of ${ }^{14} \mathrm{RKRLLK}^{19}$ were mutated (e.g., GNWLLN) were also functional in our experiments (data not shown). Thus, we conclude that the ${ }^{14}$ RKRLLK ${ }^{19}$ motif is not a NLS, and that the Nterminal 22 amino acids are not necessary for any function of eIF4AIII yet tested. That this region plays no functional role at all is suggested by its complete lack of conservation in other organisms (Fig. 1).

\section{MATERIALS AND METHODS}

\section{Plasmid construction and site-specific mutagenesis of elF4AIII}

Full-length human eIF4AIII, eIF4AI, MLN51, and N-term400 MLN51 (1-400 amino acids) cDNAs were PCR amplified with Pfu DNA polymerase (Stratagene) from a HeLa cDNA library (Clontech) and cloned into pGEMT-easy vector (Promega). eIF4AI-GST and $\mathrm{N}$-term400 MLN51-His ${ }_{6}$ expression vectors were constructed by subcloning these cDNAs into pET-HTG and pET-HMK-His, respectively (gifts from J. Kjems) (Jensen et al. 1995). Point mutants in eIF4AIII were generated by subjecting the pGEMT-easy eIF4AIII plasmid to mutagenesis using the QuickChange Site-Directed Mutagenesis Kit (Stratagene). Truncated eIF4AIII versions were generated by PCR from pGEMT-easy eIF4AIII and recloned into pGEMTeasy. After all mutants were verified by sequencing, mutant eIF4AIII cDNAs were subcloned into pEGFP-C3 (Clontech), p3XFLAG-CMV (Sigma), and pET-HTG vectors, to express N-terminal GFP-, $\mathrm{N}$-terminal Flag- and C-terminal GST-fusions, respectively. Fulllength MLN51 cDNA was subcloned into p3XFLAG-CMV to express N-terminal Flag-MLN51.

\section{RNAi and NMD rescue analysis}

SiRNAs targeting endogenous eIF4AIII mRNA were directed against the $3^{\prime}$-UTR sequence 5'-AAGCAGCAGATCAGTGGGATGAG-3'. RNAi protocols were as previously described (Elbashir et al. 2001; Mendell et al. 2002; Shibuya et al. 2004). Briefly, 7C4 HeLa cells growing in 35-mm dishes were transfected with $40 \mathrm{nM}$ siRNA duplex $\pm 800 \mathrm{ng}$ of p3XFLAG-eIF4AIII constructs using $2.5 \mu \mathrm{L}$ of lipofectamine2000 (Invitrogen) according to the manufacturer's protocol. Cells were harvested $48 \mathrm{~h}$ later. Under these conditions, endogenous eIF4AIII levels were reduced by $\sim 70 \%$ (data not shown). For Northern blotting, $5 \mu \mathrm{g}$ of total RNA, isolated with TRI-Reagent (Molecular Research Center), was separated on a 1\% agarose/formaldehyde gel, transferred to a nylon membrane, and probed with ${ }^{32} \mathrm{P}$-labeled, random-primed DNA fragments. TCR- $\beta$ VDJ and human $\beta$-actin probes were derived from $\mathrm{p} \beta 322$ and $\mathrm{pAC1}$ plasmids, respectively, as previously described (Muhlemann et al. 2001).

\section{Expression and purification of recombinant proteins}

GST- and $\mathrm{His}_{6}$-fusions were expressed in BL21-CodonPlus(DE3) (Stratagene) cells grown to mid-log phase and induced at $37^{\circ} \mathrm{C}$ for $5 \mathrm{~h}$ with $0.5 \mathrm{mM}$ isopropyl $\beta$-D-thiogalactopyranoside (IPTG). For purification of GST-fusions, cell pellets from 500-mL cultures were resuspended in $8 \mathrm{~mL}$ GST-purification buffer $(20 \mathrm{mM}$ Tris$\mathrm{HCl}$ at $\mathrm{pH} 8.0,300 \mathrm{mM} \mathrm{NaCl}, 10 \%$ [v/v] glycerol, $1 \mathrm{mM}$ DTT, 1 mM EDTA, $1 \mathrm{mM}$ PMSF) and sonicated. Triton X-100 was added to a final concentration of $0.5 \%(\mathrm{v} / \mathrm{v})$ and the suspensions kept on ice for $30 \mathrm{~min}$ more with occasional mixing. Lysates were clarified by centrifugation and incubated with $200 \mu \mathrm{L}$ (bed volume) glutathione-sepharose beads (Amersham Biosciences) at $4^{\circ} \mathrm{C}$ for $1 \mathrm{~h}$. Beads were washed twice with GST-purification buffer supplemented with $0.1 \%(\mathrm{v} / \mathrm{v})$ Triton X-100 and then once with GSTpurification buffer without Triton X-100. Bound proteins were eluted with GST-elution buffer $(100 \mathrm{mM}$ Tris- $\mathrm{HCl}$ at $\mathrm{pH} 8.0,120 \mathrm{mM}$ $\mathrm{NaCl}, 20 \mathrm{mM}$ glutathione) and dialyzed in storage buffer $(50 \mathrm{mM}$ $\mathrm{KCl}, 10 \mathrm{mM}$ HEPES at pH 8.0, 10\% [v/v] glycerol, $0.5 \mathrm{mM}$ DTT).

For purification of $\mathrm{His}_{6}$-fusions, cell pellets from $500-\mathrm{mL}$ cultures were suspended in $8 \mathrm{~mL}$ His-purification buffer $(50 \mathrm{mM}$ $\mathrm{NaH}_{2} \mathrm{PO}_{4}$ at $\mathrm{pH} 8.0,300 \mathrm{mM} \mathrm{NaCl}, 5 \%$ [v/v] glycerol, $20 \mathrm{mM}$ imidazol, $1 \mathrm{mM}$ PMSF) and sonicated. Clarified lysates were incubated with $400 \mu \mathrm{L}$ (bed volume) Ni-NTA agarose beads (Qiagen) at $4^{\circ} \mathrm{C}$ for $1 \mathrm{~h}$. After two washes with His-purification buffer, beads were transferred to a column and washed with 30 bed volumes His-wash buffer $\left(50 \mathrm{mM} \mathrm{NaH}_{2} \mathrm{PO}_{4}\right.$ at $\mathrm{pH} 6.0,300 \mathrm{mM}$ $\mathrm{NaCl}, 5 \%$ [v/v] glycerol, $20 \mathrm{mM}$ imidazol, $1 \mathrm{mM} \mathrm{PMSF}$ ). Bound proteins were eluted with His-elution buffer $\left(50 \mathrm{mM} \mathrm{NaH}_{2} \mathrm{PO}_{4}\right.$ at pH 6.0, $300 \mathrm{mM} \mathrm{NaCl}, 5 \%$ [v/v] glycerol, $300 \mathrm{mM}$ imidazol, $1 \mathrm{mM}$ PMSF) and dialyzed into $20 \mathrm{mM}$ Tris- $\mathrm{HCl}$ (pH 8.0), $100 \mathrm{mM}$ $\mathrm{NaCl}, 12 \mathrm{mM} \mathrm{MgCl}_{2}$ for radioactive labeling.

For ATPase assays, wild-type and mutant eIF4AIII-GST fusions were initially isolated on glutathione-sepharose beads as described above and further purified using a HiTrap heparin column (Pharmacia) to reduce contaminating E. coli NTPases. Purified proteins were dialyzed in $20 \mathrm{mM}$ Tris- $\mathrm{HCl}$ ( $\mathrm{pH} 7.5), 4 \mathrm{mM}$ magnesium diacetate, $2 \mathrm{mM}$ DTT, $150 \mathrm{mM}$ potassium acetate, $10 \%(\mathrm{v} / \mathrm{v})$ glycerol. Protein concentrations were estimated by SDS-PAGE analysis of twofold dilution series in parallel with known quantities of protein markers (data not shown).

\section{Immunoprecipitation and GST pull-down assay for protein-protein interaction}

For the coimmunoprecipitation of transfected proteins in vivo, human HEK293T cells were plated on $60-\mathrm{mm}$ plates and transfected using FuGENE6 reagent (Roche) with $2 \mu \mathrm{g}$ of individual p3XFLAG-eIF4AIII constructs. After $24 \mathrm{~h}$, cells were harvested, washed in $1 \times$ PBS, resuspended in lysis buffer $(10 \mathrm{mM}$ Tris- $\mathrm{HCl}$ at $\mathrm{pH}$ 8.0, $200 \mathrm{mM} \mathrm{NaCl}, 0.1 \%$ [v/v] Triton X-100, $1 \mathrm{mM}$ PMSF) and sonicated. Cellular debris was removed by centrifugation at $10,000 \mathrm{~g}$ for $10 \mathrm{~min}$ at $4^{\circ} \mathrm{C}$. Following RNase A $(10 \mu \mathrm{g} / \mathrm{mL})$ treatment for $15 \mathrm{~min}$ on ice, the cleared cell extracts were recentrifuged and supernatants incubated with $1 \mu \mathrm{L}$ of anti-Flag antibody (Sigma) for $2 \mathrm{~h}$ at $4^{\circ} \mathrm{C}$. Next, $10 \mu \mathrm{L}$ (bed volume) of protein $\mathrm{G}$ beads (Amersham Biosciences) were added and incubation continued with rocking for an additional $2 \mathrm{~h}$ at $4^{\circ} \mathrm{C}$. After seven washes with lysis buffer, bound proteins were eluted in SDS- 
PAGE sample buffer. For Western blotting, eluted proteins were separated on a $13 \%$ SDS-PAGE, transferred to nitrocellulose, blocked in 5\% nonfat milk, and incubated with anti-Flag and antiMagoh antibodies. For Figure 8, HEK293T cells plated on 60-mm plates were cotransfected with $1 \mu \mathrm{g}$ of pEGFP-eIF4AIII construct and $1 \mu \mathrm{g}$ of p3XFLAG-full length MLN51. Cells were harvested $24 \mathrm{~h}$ post-transfection, and treated as above. GFP-eIF4AIII was detected by mouse anti-GFP antibody (JL-8, BD Biosciences).

For the GST pull-down assay (Fig. 8), recombinant N-term400 MLN51 expressed from pET-HMK-His, which also contains a C-terminal $\mathrm{His}_{6}$-tag and an $\mathrm{N}$-terminal heart muscle kinase (HMK) phosphorylation site, was labeled with ${ }^{32} \mathrm{P}$-ATP in reaction buffer $\left(20 \mathrm{mM}\right.$ Tris- $\mathrm{HCl}$ at $\left.\mathrm{pH} 8.0,100 \mathrm{mM} \mathrm{NaCl}, 12 \mathrm{mM} \mathrm{MgCl}_{2}\right)$ for $45 \mathrm{~min}$ at $30^{\circ} \mathrm{C}$ using $\mathrm{HMK}$ kinase (Sigma). ${ }^{32} \mathrm{P}$-labeled $\mathrm{N}$ term400 MLN51 was mixed with $200 \mathrm{ng}$ purified eIF4AIII-GST protein in $500 \mu \mathrm{L}$ GST-binding buffer $(10 \mathrm{mM}$ Tris- $\mathrm{HCl}$ at $\mathrm{pH} 8.0$, $200 \mathrm{mM} \mathrm{NaCl}, 0.1 \%$ [v/v] Triton X-100, 5\% [v/v] glycerol, $1 \mathrm{mM}$ PMSF, $10 \mu \mathrm{g} / \mathrm{mL}$ RNaseA). After rotation for $90 \mathrm{~min}$ at $4^{\circ} \mathrm{C}, 10 \mu \mathrm{L}$ (bed volume) glutathione-sepharose beads (Amersham Biosciences) were added and incubation continued with rocking for $1 \mathrm{~h}$ at $4^{\circ} \mathrm{C}$. Beads were subsequently washed seven times with GST-binding buffer without RNase A. Coprecipitated proteins were eluted into SDS sample buffer and separated on a 12\% SDS-PAGE, which was developed with both Coomassie staining and phosphorimaging.

\section{In vitro splicing and protein-RNA interactions}

Template preparation, in vitro transcription, and the in vitro splicing reactions were performed as previously described (Shibuya et al. 2004). Briefly, $10 \mu \mathrm{L}$ splicing reactions contained $4 \mu \mathrm{L}$ HeLa nuclear extract, $1 \mu \mathrm{L} 10 \times$ splicing buffer, and $1 \mu \mathrm{L}(10,000$ cpm) ${ }^{32}$ P-labeled AdML pre-mRNA, plus 200 ng eIF4AIII-GST protein. After $75 \mathrm{~min}$ at $30^{\circ} \mathrm{C}, 5 \mu \mathrm{g}$ heparin and $10 \mu \mathrm{L}$ (bed volume) glutathione-sepharose beads (Amersham Biosciences) were added in $500 \mu \mathrm{L}$ GST-binding buffer without RNase A, and incubation continued with rocking for $1 \mathrm{~h}$ at $4^{\circ} \mathrm{C}$. After seven washes with GST-binding buffer without RNase A, precipitated RNAs were eluted and separated on $15 \%$ denaturing polyacrylamide gels and detected by phosphorimaging.

\section{ATPase assays}

ATPase reactions $(20 \mu \mathrm{L})$ contained $20 \mathrm{mM}$ Tris- $\mathrm{HCl}(\mathrm{pH} 7.5), 4$ $\mathrm{mM}$ magnesium diacetate, $2 \mathrm{mM}$ DTT, $150 \mathrm{mM}$ potassium acetate, $5 \%(\mathrm{v} / \mathrm{v})$ glycerol, $0.5 \mathrm{mM}$ ATP, $0.015 \mu \mathrm{M}\left[\gamma^{-32}{ }^{32}\right.$ ]ATP, $5 \mu \mathrm{M}$ poly $(\mathrm{U})$ as calculated in 20-mer units, and $100 \mathrm{ng}$ of GST-fusion proteins. Reactions were incubated at $30^{\circ} \mathrm{C}$ for the indicated time periods and $2-\mu \mathrm{L}$ aliquots quenched with an equal volume of 25 mM EDTA ( $\mathrm{pH}$ 8.0). Products were separated on polyethyleneimine cellulose thin layer chromatography (PEI-TLC) plates using $0.5 \mathrm{M} \mathrm{LiCl}, 1 \mathrm{M}$ formic acid as a running buffer. ${ }^{32} \mathrm{Pi}$ was calculated as a fraction of total radioactivity $\left({ }^{32} \mathrm{Pi}+\left[\gamma_{-}{ }^{32} \mathrm{P}\right] \mathrm{ATP}\right)$. The value of ${ }^{32} \mathrm{Pi}$ at $t=0$ was subtracted as background.

\section{Immunofluorescence microscopy}

HeLa cells grown on coverslips in DMEM medium (Gibco BRL) were transfected with each pEGFP-eIF4AIII construct by Lipofec- tamine2000 (Invitrogen). After incubating for $24 \mathrm{~h}$, fixation and immunostaining were carried out as previously described (Muhlemann et al. 2001; Shibuya et al. 2004). SC35 splicing factor was detected with mouse anti-SC35 antibody (Sigma) and rhodaminelabeled anti-mouse secondary antibody.

\section{ACKNOWLEDGMENTS}

We thank Elisa Izaurralde, Nahum Sonenberg, and Miles Wilkinson for plasmids, antibodies, and cell lines. We are grateful to Chia Chan, Gideon Dreyfuss, Maria Ferraiuolo, Nahum Sonenberg, and Hervé Le Hir for sharing unpublished observations. We additionally thank Michael Rosbash and members of our laboratory, especially Frederick LaRiviere and Kristine O'Brien, for critical reading of and comments on the manuscript, and Nadja Rozovsky and Aimee Buterworth for technical assistance with the ATPase assays. M.J.M. is an HHMI Investigator. This work was supported in part by NIH grant GM53007 (M.J.M.) and a research stipend from the Alfred Benzon Foundation (T.Ø.T.). M.E.S is an HHMI fellow of the Life Science Research Foundation.

Received August 9, 2005; accepted December 8, 2005.

\section{REFERENCES}

Ballut, L., Marchadier, B., Baguet, A., Tomasetto, C., Seraphin, B., and Le Hir, H. 2005. The exon junction core complex is locked onto RNA by inhibition of eIF4AIII ATPase activity. Nat. Struct. Mol. Biol. 12: 861-869.

Caruthers, J.M and McKay, D.B. 2002. Helicase structure and mechanism. Curr. Opin. Struct. Biol. 12: 123-133.

Caruthers, J.M., Johnson, E.R., and McKay, D.B. 2000. Crystal structure of yeast initiation factor 4A, a DEAD-box RNA helicase. Proc. Natl. Acad. Sci. 97: 13080-13085.

Chan, C.C., Dostie, J., Diem, M.D., Feng, W., Mann, M., Rappsilber, J., and Dreyfuss, G. 2004. eIF4A3 is a novel component of the exon junction complex. RNA 10: 200-209.

Conti, E. and Izaurralde, E. 2005. Nonsense-mediated mRNA decay: Molecular insights and mechanistic variations across species. Curr. Opin. Cell Biol. 17: 316-325.

Dreyfuss, G., Kim, V.N., and Kataoka, N. 2002. Messenger-RNAbinding proteins and the messages they carry. Nat. Rev. Mol. Cell Biol. 3: 195-205.

Elbashir, S.M., Harborth, J., Lendeckel, W., Yalcin, A., Weber, K., and Tuschl, T. 2001. Duplexes of 21-nucleotide RNAs mediate RNA interference in cultured mammalian cells. Nature 411: 494-498.

Fairman, M.E., Maroney, P.A., Wang, W., Bowers, H.A., Gollnick, P., Nilsen, T.W., and Jankowsky, E. 2004. Protein displacement by DExH/D "RNA helicases" without duplex unwinding. Science 304: 730-734.

Ferraiuolo, M.A., Lee, C.S., Ler, L.W., Hsu, J.L., Costa-Mattioli, M., Luo, M.J., Reed, R., and Sonenberg, N. 2004. A nuclear translationlike factor eIF4AIII is recruited to the mRNA during splicing and functions in nonsense-mediated decay. Proc. Natl. Acad. Sci. 101: $4118-4123$.

Gehring, N.H., Kunz, J.B., Neu-Yilik, G., Breit, S., Viegas, M.H., Hentze, M.W., and Kulozik, A.E. 2005. Exon-junction complex components specify distinct routes of nonsense-mediated mRNA decay with differential cofactor requirements. Mol. Cell 20: $65-75$.

Hachet, O. and Ephrussi, A. 2001. Drosophila Y14 shuttles to the posterior of the oocyte and is required for oskar mRNA transport. Curr. Biol. 11: 1666-1674. 
Hernandez, G. and Vazquez-Pianzola, P. 2005. Functional diversity of the eukaryotic translation initiation factors belonging to eIF4 families. Mech. Dev. 122: 865-876.

Holzmann, K., Gerner, C., Poltl, A., Schafer, R., Obrist, P., Ensinger, C., Grimm, R., and Sauermann, G. 2000. A human common nuclear matrix protein homologous to eukaryotic translation initiation factor 4A. Biochem. Biophys. Res. Commun. 267: 339344.

Jankowsky, E., Gross, C.H., Shuman, S., and Pyle, A.M. 2001. Active disruption of an RNA-protein interaction by a DExH/D RNA helicase. Science 291: 121-125.

Jensen, T.H., Jensen, A., and Kjems, J. 1995. Tools for the production and purification of full-length, $\mathrm{N}$ - or C-terminal 32P-labeled protein, applied to HIV-1 Gag and Rev. Gene 162: 235-237.

Jurica, M.S. and Moore, M.J. 2003. Pre-mRNA splicing: Awash in a sea of proteins. Mol. Cell 12: 5-14.

Jurica, M.S., Sousa, D., Moore, M.J., and Grigorieff, N. 2004. Threedimensional structure of $\mathrm{C}$ complex spliceosomes by electron microscopy. Nat. Struct. Mol. Biol. 11: 265-269.

Kapp, L.D. and Lorsch, J.R. 2004. The molecular mechanics of eukaryotic translation. Annu. Rev. Biochem. 73: 657-704.

Kim, J.L., Morgenstern, K.A., Griffith, J.P., Dwyer, M.D., Thomson, J.A., Murcko, M.A., Lin, C., and Caron, P.R. 1998. Hepatitis C virus NS3 RNA helicase domain with a bound oligonucleotide: The crystal structure provides insights into the mode of unwinding. Structure 6: 89-100.

Lander, E.S., Linton, L.M., Birren, B., Nusbaum, C., Zody, M.C., Baldwin, J., Devon, K., Dewar, K., Doyle, M., FitzHugh, W., et al. 2001. Initial sequencing and analysis of the human genome. Nature 409: 860-921.

Le Hir, H., Izaurralde, E., Maquat, L.E., and Moore, M.J. 2000. The spliceosome deposits multiple proteins 20-24 nucleotides upstream of mRNA exon-exon junctions. EMBO J. 19: 6860-6869.

Le Hir, H., Gatfield, D., Izaurralde, E., and Moore, M.J. 2001. The exon-exon junction complex provides a binding platform for factors involved in mRNA export and nonsense-mediated mRNA decay. EMBO J. 20: 4987-4997.

Le Hir, H., Nott, A., and Moore, M.J. 2003. How introns influence and enhance eukaryotic gene expression. Trends Biochem. Sci. 28: 215-220.

Lejeune, F. and Maquat, L.E. 2005. Mechanistic links between nonsense-mediated mRNA decay and pre-mRNA splicing in mammalian cells. Curr. Opin. Cell Biol. 17: 309-315.

Li, Q., Imataka, H., Morino, S., Rogers G.W.Jr., , Richter-Cook, N.J., Merrick, W.C., and Sonenberg, N. 1999. Eukaryotic translation initiation factor 4AIII (eIF4AIII) is functionally distinct from eIF4AI and eIF4AII. Mol. Cell. Biol. 19: 7336-7346.

Linder, P., Tanner, N.K., and Banroques, J. 2001. From RNA helicases to RNPases. Trends Biochem. Sci. 26: 339-341.

Lorsch, J.R. and Herschlag, D. 1998. The DEAD box protein eIF4A. 1. A minimal kinetic and thermodynamic framework reveals coupled binding of RNA and nucleotide. Biochemistry 37: 2180-2193.

Maquat, L.E. 2004. Nonsense-mediated mRNA decay: Splicing, translation and mRNP dynamics. Nat. Rev. Mol. Cell Biol. 5: 89-99.

2005. Nonsense-mediated mRNA decay in mammals. J. Cell Sci. 118: 1773-1776.

Mendell, J.T., ap Rhys, C.M., and Dietz, H.C. 2002. Separable roles for rent1/hUpf1 in altered splicing and decay of nonsense transcripts. Science 298: 419-422.

Mohr, S.E., Dillon, S.T., and Boswell, R.E. 2001. The RNA-binding protein Tsunagi interacts with Mago Nashi to establish polarity and localize oskar mRNA during Drosophila oogenesis. Genes \& Dev. 15: 2886-2899.

Muhlemann, O., Mock-Casagrande, C.S., Wang, J., Li, S., Custodio, N., Carmo-Fonseca, M., Wilkinson, M.F., and Moore, M.J. 2001. Precursor RNAs harboring nonsense codons accumulate near the site of transcription. Mol. Cell 8: 33-43.
Nott, A., Meislin, S.H., and Moore, M.J. 2003. A quantitative analysis of intron effects on mammalian gene expression. RNA 9: 607-617.

Nott, A., Le Hir, H., and Moore, M.J. 2004. Splicing enhances translation in mammalian cells: An additional function of the exon junction complex. Genes \& Dev. 18: 210-222.

Palacios, I.M. 2002. RNA processing: Splicing and the cytoplasmic localisation of mRNA. Curr. Biol. 12: R50-52.

Palacios, I.M., Gatfield, D., St. Johnston, D., and Izaurralde, E. 2004. An eIF4AIII-containing complex required for mRNA localization and nonsense-mediated mRNA decay. Nature 427: 753-757.

Pause, A. and Sonenberg, N. 1992. Mutational analysis of a DEAD box RNA helicase: The mammalian translation initiation factor eIF-4A. EMBO J. 11: 2643-2654.

Pause, A., Methot, N., and Sonenberg, N. 1993. The HRIGRXXR region of the DEAD box RNA helicase eukaryotic translation initiation factor $4 \mathrm{~A}$ is required for RNA binding and ATP hydrolysis. Mol. Cell. Biol. 13: 6789-6798.

Pause, A., Methot, N., Svitkin, Y., Merrick, W.C., and Sonenberg, N. 1994. Dominant negative mutants of mammalian translation initiation factor eIF-4A define a critical role for eIF-4F in capdependent and cap-independent initiation of translation. EMBO J. 13: $1205-1215$.

Pendle, A..F, Clark, G.P., Boon, R., Lewandowska, D., Lam, Y.W., Andersen, J., Mann, M., Lamond, A.I., Brown, J.W., and Shaw, P.J. 2005. Proteomic analysis of the Arabidopsis nucleolus suggests novel nucleolar functions. Mol. Biol. Cell 16: 260-269.

Pettersen, E.F., Goddard, T.D., Huang, C.C., Couch, G.S., Greenblatt, D.M., Meng, E.C., and Ferrin, T.E. 2004. UCSF Chimera-A visualization system for exploratory research and analysis. J. Comput. Chem. 25: 1605-1612.

Rocak, S. and Linder, P. 2004. DEAD-box proteins: The driving forces behind RNA metabolism. Nat. Rev. Mol. Cell Biol. 5: 232-241.

Rogers Jr., G.W., Komar, A.A., and Merrick, W.C. 2002. eIF4A: The godfather of the DEAD box helicases. Prog. Nucleic Acid Res. Mol. Biol. 72: 307-331.

Rozen, F., Pelletier, J., Trachsel, H., and Sonenberg, N. 1989. A lysine substitution in the ATP-binding site of eucaryotic initiation factor 4A abrogates nucleotide-binding activity. Mol. Cell. Biol. 9: 4061-4063.

Sanner, M.F., Olson, A.J., and Spehner, J.C. 1996. Reduced surface: An efficient way to compute molecular surfaces. Biopolymers 38: 305-320.

Schwede, T., Kopp, J., Guex, N., and Peitsch, M.C. 2003. SWISSMODEL: An automated protein homology-modeling server. Nucleic Acids Res. 31: 3381-3385.

Schwer, B. 2001. A new twist on RNA helicases: DExH/D box proteins as RNPases. Nat. Struct. Biol. 8: 113-116.

Shibuya, T., Tange, T.O, Sonenberg, N., and Moore, M.J. 2004. eIF4AIII binds spliced mRNA in the exon junction complex and is essential for nonsense-mediated decay. Nat. Struct. Mol. Biol. 11: 346-351.

Subramanya, H.S., Bird, L.E., Brannigan, J.A., and Wigley, D.B. 1996. Crystal structure of a DExx box DNA helicase. Nature 384: 379-383.

Svitkin, Y.V., Pause, A., Haghighat, A., Pyronnet, S., Witherell, G., Belsham, G.J., and Sonenberg, N. 2001. The requirement for eukaryotic initiation factor $4 \mathrm{~A}$ (elF4A) in translation is in direct proportion to the degree of mRNA $5^{\prime}$ secondary structure. RNA 7: 382-394.

Tange, T.O., Nott, A., and Moore, M.J. 2004. The ever-increasing complexities of the exon junction complex. Curr. Opin. Cell Biol. 16: $279-284$.

Tange, T.O., Shibuya, T., Jurica, M.S., and Moore, M.J. 2005. Biochemical analysis of the EJC reveals two new factors and a stable tetrameric protein core. RNA 11: 1869-1883.

Tanner, N.K. and Linder, P. 2001. DExD/H box RNA helicases: From generic motors to specific dissociation functions. Mol. Cell 8: 251-262. 
Tanner, N.K., Cordin, O., Banroques, J., Doere, M., and Linder, P. 2003. The Q motif: A newly identified motif in DEAD box helicases may regulate ATP binding and hydrolysis. Mol. Cell 11: 127-138.

Venter, J.C., Adams, M.D., Myers, E.W., Li, P.W., Mural, R.J., Sutton, G.G., Smith, H.O., Yandell, M., Evans, C.A., Holt, R.A., et al. 2001. The sequence of the human genome. Science 291: 1304-1351.

Weinstein, D.C., Honore, E., and Hemmati-Brivanlou, A. 1997. Epidermal induction and inhibition of neural fate by translation initiation factor 4AIII. Development 124: 4235-4242.
Wiegand, H.L., Lu, S., and Cullen, B.R. 2003. Exon junction complexes mediate the enhancing effect of splicing on mRNA expression. Proc. Natl. Acad. Sci. 100: 11327-11332.

Yao, N., Hesson, T., Cable, M., Hong, Z., Kwong, A.D., Le, H.V., and Weber, P.C. 1997. Structure of the hepatitis C virus RNA helicase domain. Nat. Struct. Biol. 4: 463-467.

Zhou, Z., Luo, M.J., Straesser, K., Katahira, J., Hurt, E., and Reed, R. 2000. The protein Aly links pre-messenger-RNA splicing to nuclear export in metazoans. Nature 407: 401-405. 

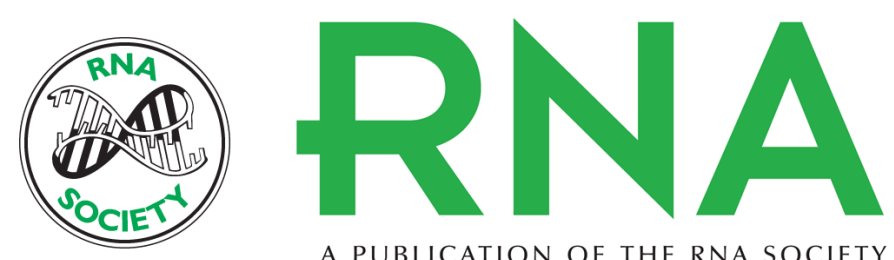

A PUBLICATION OF THE RNA SOCIETY

\title{
Mutational analysis of human elF4Alll identifies regions necessary for exon junction complex formation and nonsense-mediated mRNA decay
}

\author{
TOSHIHARU SHIBUYA, THOMAS Ø. TANGE, M. ELIZABETH STROUPE, et al.
}

RNA 2006 12: 360-374

References This article cites 59 articles, 21 of which can be accessed free at:

http://rnajournal.cshlp.org/content/12/3/360.full.html\#ref-list-1

License

Email Alerting Receive free email alerts when new articles cite this article - sign up in the box at the

Service top right corner of the article or click here. 